\title{
FEMINIST ENCOUNTERS: A JOURNAL OF CRITICAL STUDIES IN CULTURE AND POLITICS
}

Founded in 2017, Feminist Encounters is a journal committed to argument and debate, in the tradition of historical feminist movements.

In the wake of the growing rise of the Right across the world, openly neo-fascist national sentiments, and rising conservative populism, we feminists all over the world are needing to remobilise our energies to protect and advance gender rights.

Feminist Encounters provides a forum for feminist theorists, scholars, and activists to communicate with each other, to better educate ourselves on international issues and thus promote more global understanding, and to enhance our critical tools for fighting for human rights.

Feminism is an intellectual apparatus, a political agenda, and a programme for social change. Critical analysis of how gender discourses produce cultural identities and social practices within diverse lived realities is key to this change. We need to think more sharply in order to strategise well: as the discourses of conservatism renew and invigorate themselves, so we as feminist scholars need to be refining our amazonic swords in order not just to respond effectively but also to innovate our own ideas for equality and social justice.

We are, of course, committed to intersectionality, a vital lens through which to see the contours of race/ethnicity, class, sexuality, age/ability, and explore how gendered scripts get lived, and filtered through these specificities of cultural organisation. Lived experience is never codified in terms of gender alone, and so our research will always be sensitive to the nexus of lived oppressions.

The journal has a large editorial board and journal team, consisting of over forty scholars in twenty countries. This is deliberately inclusive in order that we can promote diversity and engage with different concerns from across the world. Our aim is not to simply talk to ourselves, reconfirming our localised assumptions, but to generate feminist encounters across regions, even if this is sometimes uncomfortable. Globalisation has been a triumph of neoliberalism, but digital technologies have also flattened and reduced the distance between us in dramatic ways, so that now we can talk to each other with unanticipated ease.

This new access to each others' voices has also brought challenges to the way we think and do things, so that being a feminist today might be quite a different prospect to a person living in China, Iran, Norway, South Africa or the UK. Second Wave Feminism used the idea of 'sisterhood' to invoke solidarity between women. I've always rather liked Andrea Dworkin's claim, though, that: "Feminism is a political practice of fighting male supremacy in behalf of women as a class, including all the women you don't like, including all the women you don't want to be around, including all the women who used to be your best friends whom you don't want anything to do with anymore." The notion of sisterhood was challenged by Black feminists in the 1980s as being too conceptually white, thus bell hooks' trenchant critique that: "the idea of 'common oppression' was a false and corrupt platform disguising and mystifying the true nature of women's varied and complex social reality". In the 1990s and 2000s it has been fair to say that feminist theory and Feminist Studies since have engaged more intentionally and deliberately with intersectionality - though Jennifer Baumgardner did caution us that: "Sisterhood was never about everybody agreeing ....".

For our journal, sisterhood must expand and embrace our transgender allies and our men friends, reminding us that sibling relationships are rarely straightforward or inevitably blessed by golden moments of total affinity. Thus, Feminist Encounters welcomes the opportunity for new kinds of international discussions in the spirit of collaboration and critical intellectual enquiry. We hope for productive agreement and disagreement, and the shared struggle of fighting gender oppression, with our minds, hearts, and bodies, as the times demand. 